\title{
Luxation of the eyeball
}

\author{
H N CHHABRA AND A M S KAWUMA
}

From the Department of Ophthalmology, University Teaching Hospital, Lusaka, Zambia

SUMmARY Luxation of the eyeball in two African patients is reported for its rarity. It followed minor trauma to the face and was reduced in both cases without permanent visual disability.

The following two cases of luxation of the eyeball were seen in 1983.

\section{Case reports}

CASE 1

A 27-year-old African male fell down following unexplained dizziness in the evening of 12 September 1983. He dropped on his face. When he got up he found his left eye hanging out and was unable to close the eyelids on it. In spite of dull pain he reported next morning for a medical opinion.

On examination there were no marks of injury on the forehead or face. The left eye appeared proptosed and the two eyelids hidden completely behind the eyeball. The conjunctiva was congested and chemosed. The cornea had diffused superficial haze masking a view of the interior of eye. Vision was reduced to counting fingers close to the face. The right eye was normal.

Under local anaesthesia traction was applied with the help of lid sutures applied to the lid margins. The

Correspondence to Dr H N Chhabra, School of Medicine, PO Box A-178, Avondale, Harare, Zimbabwe.

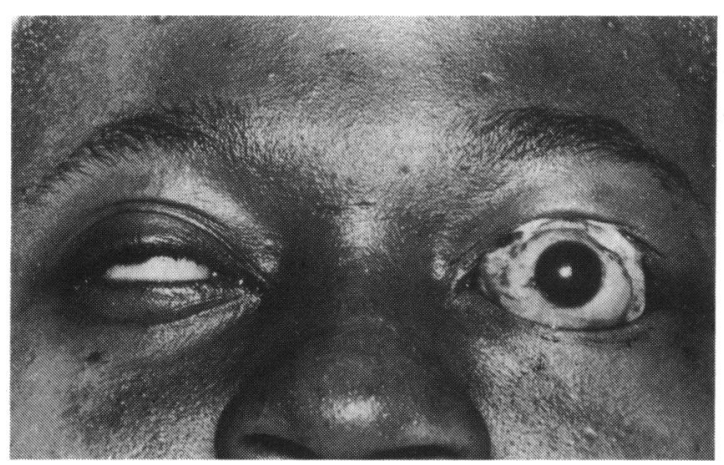

Fig. 1 Luxation of left eyelid margins rolled behind the proptosed eye. eyelids were pulled over the globe and the sutures tied to achieve a sort of temporary tarsorrhaphy. The lid sutures were cut apart later the same day. The eyeball appeared less proptosed and more mobile. Tetracycline eye ointment was applied topically and the eye bandaged with a pad. Ten days later the cornea had cleared completely, and visual acuity returned to $6 / 9$ in this eye. There was $2 \mathrm{~mm}$ residual proptosis and mild tenonitis at the lateral canthus at the time of discharge from hospital.

\section{CASE 2}

A 14-year-old African female hit her forehead and left eye against the glass of a window swung towards her by a sudden gust of wind on the morning of 26 September 1983. She felt some discomfort in the left eye and realised she could not close it. She reported within two hours of injury.

On examination there was no external mark of injury to her forehead or face. The left eye was proptosed, with the lid margins rolled in behind the globe (Fig. 1). Ocular movements were absent. The conjunctiva was congested and the cornea somewhat hazy. Vision was finger counting at $1 \mathrm{~m}$. Only a hazy

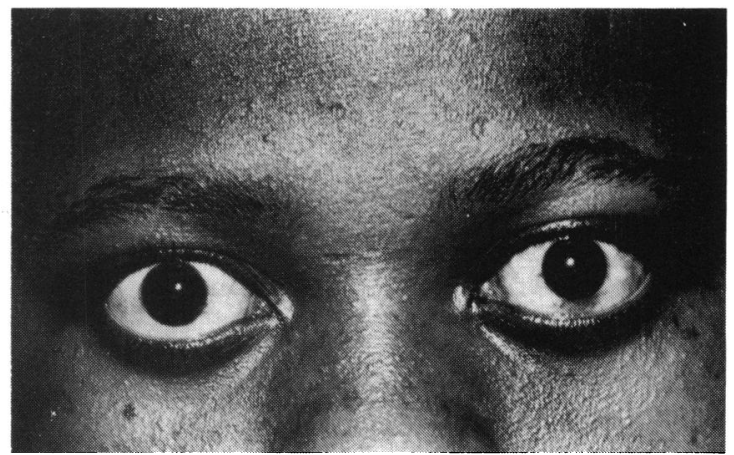

Fig. 2 The left eye after reduction of luxation. 
view of fundus could be obtained. There was no intraocular haemorrhage.

Under local anaesthesia the lids were pulled forwards and the eyeball pressed back in place. The eye was pad-bandaged after application of tetracycline eye ointment. On the third day (Fig. 2), after reposition the proptosis was less $(5 \mathrm{~mm}$ on exophthalmometry), and all movements except elevation had recovered. The fundus appeared normal. The central field showed a $5-7^{\circ}$ paracentral, almost ring scotoma, some $12^{\circ}$ from the point of fixation. She was discharged a week later with $6 / 6$ visual acuity and full ocular movements. The central field defect continued, though reduced, till a week later. The proptosis subsided completely.

\section{Discussion}

Luxation of the eyeball is a condition in which there is forward displacement of the eye so that the eyelids close behind it. It is a rare sequel to major trauma to the orbital wall. Spontaneous luxation after trivial injury to forehead, as in our cases, is extremely rare. The factors which predispose to easy luxation include (1) shallow orbits such as are seen in infants or in cases of congenital craniofacial anomaly; (2) space-occupying lesions of the orbit; and (3) laxity of fascial ligaments and orbital muscles. ${ }^{1}$

Both our patients were young black Africans. Lyle and $\mathrm{McGavic}^{2}$ have recorded shallow orbits as a racial factor in blacks. This could not be confirmed radiologically in our cases owing to inadequate supply of $x$-ray films at that time. The patients were neither obese nor the eyes prominent. There was no evidence of space-occupying orbital growth, as the eyes settled completely after reduction. Laxity of ligaments or extraocular muscles or both may also have been a contributory factor, since such anomalies have been reported in blacks by Almeda ${ }^{3}$ and Gillespie. ${ }^{4}$

Generally luxation does little harm if reduced early. The reduction is achieved by firmly pulling the eyelids forwards and pressing the globe backwards at the same time. Unless there is associated trauma to the bony orbit or soft tissues, timely reposition gives immediate relief and restores visual functions. The condition, though rare and seen once in the lifetime of an ophthalmologist, may perhaps be especially encountered in African patients.

\section{References}

1 Duke-Elder S. System of ophthalmology. London: Kimpton, 1974; 13(2): 1233.

2 Lyle DJ, McGavic JS. The cause of voluntary forward luxation of the eyeball. A case report with anatomical findings at necropsy. Am J Ophthalmol 1936; 19: 316-20.

3 Almeida A. Willkürlich hervorgerufene Luxation des Augapfels. Klin Monatsbl Augenheilkd 1932; 88: 223-5.

4 Gillespie FD. Subluxation of the globes. South Med J 1964; 57: 216-8.

Accepted for publication 6 June 1985. 